\title{
Optimization of the Energy Performance of a Low Energy House Based on Sensitivity Analysis
}

\author{
Anna Sedláková, Vladimír Geletka \\ Technical University of Košice \\ Civil Engineering Faculty, Institute of Architectural Engineering \\ e-mail: anna.sedlakova@tuke.sk, vladimir.geletka@tuke.sk
}

\begin{abstract}
For buildings with for heating requirements, energy balance is based on the difference between two similarly large numbers (heat gain and heat loss) in which the calculation becomes increasingly sensitive to changes in parameters. The output of the hourly simulation method illustrates the temperature in "free-floating" mode, which unlike the requirement for heating provides better information on the thermal behavior of the building itself in order to model the dynamic response of the object to certain changes in the input data. For the purpose of the evaluation the minimum and maximum acceptable temperature and the area within the boundaries called comfort zone. In this paper a low energy house is evaluated in terms of energy performance and thermal comfort, where some parameters are altered in order to determine its sensitivity to fluctuations. The methodology is based on a sensitivity analysis (SA) and Monte Carlo simulation based on a stochastic random selection. Thermal comfort is evaluated using an adaptive thermal comfort.
\end{abstract}

Key words: uncertainty analysis, sensitivity analysis, energy performance, thermal comfort, Monte Carlo.

\section{Introduction}

A large number of parameters influence the thermal properties of architectural design, thus finding the optimal solution requires the one know the context and relationship between the input parameters that most affect the evaluated criterion or element. The effects of changes made in a local context can be seen globally in order to vary input parameters and their combinations. To serve this purpose, various optimization procedures and methods are implemented which are most often based on statistical methods. These optimization procedures are primarily aimed at optimizing the reporting criteria - objective function, or to describe the relationships between the parameters and monitoring of the criteria based on which measures are taken to reduce it. From the combination above - mentioned approaches - energy simulation and optimization it is possible to achieve a reduction in energy consumption for heating, cooling, and in turn optimize the parameters of the internal environment etc. This depends on the selected criteria and the combination of parameters 
entered into the calculation. The technique of uncertainty and sensitivity analysis (UA, SA) are nowadays frequently used as a tool for optimization. In the field of simulation of energy consumption for buildings and the indoor environment we can find some works incorporating UA and SA [1][2][3]. All these authors use UA and SA to optimize the energy performance of buildings.

\section{Evaluation of a House - Case Study}

The subject of the study involved the investigation of the impact of some design parameters on energy consumption and indoor thermal comfort for a detached passive two-storey house as depicted in Fig.1. The object is situated in Kittsee - a village near Bratislava. [4]

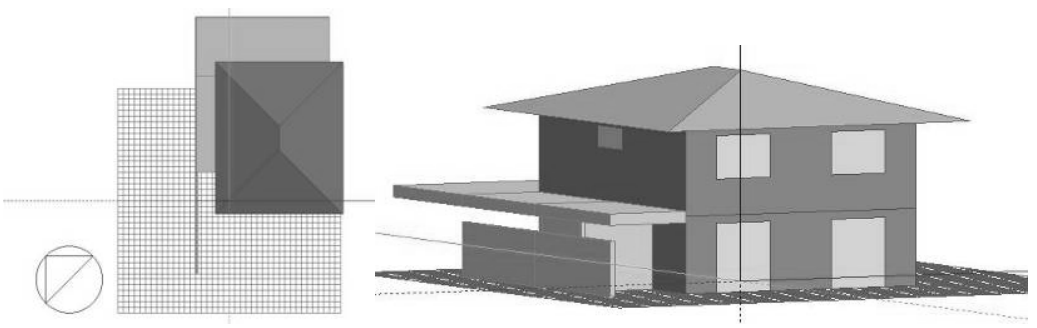

Figure 1: View of the passive House

A model is used to describe a house with input parameters listed in Table 1 and Table 2, which describes the geometric characteristic of the house, insulating values of the building envelope as well as the parameters of HVAC.

Table 1: Parameters of envelope constructions of a house

\begin{tabular}{|c|c|c|c|c|c|}
\hline \multirow{2}{*}{8 煟 } & \multirow{2}{*}{ Layes of structure } & $\mathbf{d}$ & $\rho$ & c & 2 \\
\hline & & [m] & [kg/m $\left.{ }^{3}\right]$ & [J/k, K] & [W/mo.K] \\
\hline \multirow{4}{*}{ 寻 } & Inside plaster & 0,01 & 600 & 1000 & 0,19 \\
\hline & $X_{\text {tong }} P_{2-400}$ PD & 0,25 & 400 & 870 & 0,119 \\
\hline & Fihn wool ISOVER TF & $\mathbf{0 , 3}$ & 108 & 800 & 0,038 \\
\hline & Ouside plaster & 0,01 & 1400 & 1000 & 0,800 \\
\hline \multirow{4}{*}{ 胥炭 } & Wooden floor & 0,02 & 2000 & 2510 & 0,160 \\
\hline & Anhydnite screed & 0,05 & 1300 & 2100 & 0,250 \\
\hline & Thexponsulation EPS & $\mathbf{0 , 1}$ & 25 & 1500 & 0,032 \\
\hline & Cast concrete & 0,25 & 2000 & 1000 & 1,13 \\
\hline \multirow{4}{*}{ 苫写点 } & Plaster & 0,015 & 750 & 1060 & 0,22 \\
\hline & ISOVER Uniol & $\mathbf{0 , 4}$ & 17 & 840 & 0,038 \\
\hline & OSB plate & 0,015 & 500 & 920 & $\mathbf{0 , 1 4}$ \\
\hline & ISOVER Unimol Phus & $\mathbf{0 , 1}$ & 17 & 840 & 0,038 \\
\hline \multirow{2}{*}{8 䓪 } & & $\mathbf{U}$ & SHGC & Visible trans. & \\
\hline & & {$\left[\mathrm{W} / \mathrm{m}^{2} \cdot \mathrm{K}\right]$} & [-] & [-] & \\
\hline Window & Triple & 0,62 & 0,62 & 0,659 & \\
\hline Door & Themalbrake -isolated & 0,8 & - & - & \\
\hline
\end{tabular}


Table 2: Parameters of HVAC considered in simulation

\begin{tabular}{|c|c|c|c|}
\hline \multirow{3}{*}{ 曾 } & Activity & Domestic bedroom & \\
\hline & People & $0,04 / \mathrm{m}^{2}$ & \\
\hline & Infiltration & 0,02 ac/h & \\
\hline \multirow{5}{*}{ 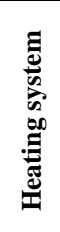 } & \multicolumn{3}{|c|}{ VAV with HR + outside air + mixed mode } \\
\hline & \multicolumn{2}{|c|}{ Heat recovery effectiveness } & 0,7 \\
\hline & \multicolumn{2}{|c|}{ Heating set point temperature } & $20^{\circ} \mathrm{C}$ \\
\hline & \multicolumn{2}{|c|}{ Natural ventilation } & $0,4 \mathrm{ac} / \mathrm{h}$ \\
\hline & \multicolumn{2}{|c|}{ Mechanical ventilation } & $0,1 \mathrm{ac} / \mathrm{h}$ \\
\hline
\end{tabular}

\section{Development of Parametric Simulation}

Energy Plus (E+) [5] simulation software is used to calculate the annual energy consumption, in-zone temperature rise and the PMV rating index of thermal comfort and number of hours outside of the thermal comfort zone. The simulation of the thermal behavior of buildings at hourly intervals was made possible using the method of thermal equilibrium, where the building was considered as one zone. Boundary conditions of the indoor climate were limited to air temperature and operative temperature. One advantage of this software is that all building and simulation information are stored in text editors files, where by using so called "EP-macro" it can be linked with other software. Several software has been established based on the E+ principle. One of them is a parametric simulation software program called JE+ [6] which uses parametric simulation based on the MonteCarlo (MC) optimization technique. MC optimization is a commonly used method, which is based on the stochastic selection of input parameters and subsequently executed by repetitive simulations Fig.2.

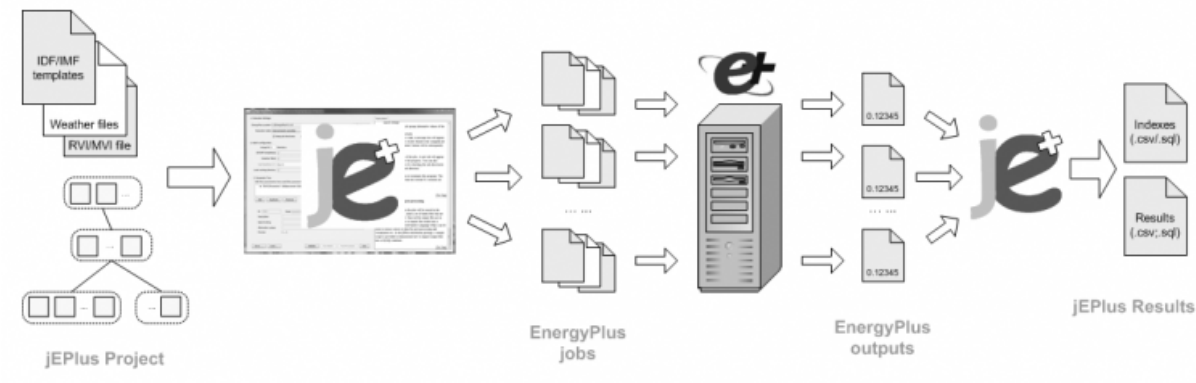

Figure 2: Principle of parametric simulation, coupling E+ and JE+ [6]

\subsection{Parametric Evaluation}

The following scenario was considered or the evaluation of the impact some parameters have on the annual energy consumption and thermal comfort of a house:

- Monthly average temperature in of the ground floor in contact with the ground was evaluated as shown Table 3,

- Scenario of future weather - according to the [7] Table 4, 
- Impact of windows, shading and their control - considering outside shading with movable blinds, which were controlled by parameters shown in Table 5,

- Properties of the glazing system used in the simulation - considered according to Tab.6.

Table 3: Monthly temperature of the ground-floor in contact with the ground

\begin{tabular}{|l|c|c|c|}
\hline \multirow{2}{*}{ Month } & \multicolumn{2}{|c|}{ Temperature $\left[{ }^{\circ} \mathrm{C}\right]$} \\
\cline { 2 - 3 } & Min. & Max. & median \\
\hline January & 15 & 20 & $\mathbf{1 8}$ \\
\hline February & 15 & 20 & $\mathbf{1 9}$ \\
\hline March & 17 & 20 & $\mathbf{1 9}$ \\
\hline April & 18 & 21 & $\mathbf{2 0}$ \\
\hline May & 19 & 24 & $\mathbf{2 0}$ \\
\hline June & 19 & 24 & $\mathbf{2 0}$ \\
\hline July & 19 & 24 & $\mathbf{2 0}$ \\
\hline August & 19 & 25 & $\mathbf{2 0}$ \\
\hline September & 19 & 23 & $\mathbf{2 0}$ \\
\hline October & 19 & 23 & $\mathbf{1 9}$ \\
\hline November & 18 & 22 & $\mathbf{1 9}$ \\
\hline December & 17 & 21 & $\mathbf{1 8}$ \\
\hline
\end{tabular}

Table 4: Scenario of future weather

\begin{tabular}{|c|c|c|c|c|c|c|c|c|c|}
\hline \multirow{3}{*}{$\stackrel{\overrightarrow{0}}{0}$} & \multicolumn{9}{|c|}{ Year } \\
\hline & \multirow{2}{*}{ Old } & \multirow{2}{*}{ Now } & \multirow{2}{*}{2012} & \multicolumn{3}{|c|}{2050} & \multicolumn{3}{|c|}{2100} \\
\hline & & & & A1b & A2 & B1 & A1b & A2 & B1 \\
\hline Bratislava & *epw & *epw & *epw & *epw & *epw & *epw & *epw & *epw & *epw \\
\hline Košice & *epw & *epw & ---- & *epw & *epw & *epw & *epw & *epw & *epw \\
\hline
\end{tabular}

Table 5: Shading, external control

\begin{tabular}{|l|c|}
\hline control & Limit \\
\hline $\mathbf{1}$ - indoor temperature & $26^{\circ} \mathrm{C}$ \\
\hline $\mathbf{2}$ - outdoor temperature & $28^{\circ} \mathrm{C}$ \\
\hline $\mathbf{3}$ - solar & $120 \mathrm{~W} / \mathrm{m}^{2}$ \\
\hline $\mathbf{4}$ - outdoor temperature + solar & $28^{\circ} \mathrm{C}+120 \mathrm{~W} / \mathrm{m}^{2}$ \\
\hline
\end{tabular}

Table 6: Properties of the glazing system

\begin{tabular}{|c|c|c|c|c|c|c|c|c|c|c|c|c|c|c|c|c|c|c|}
\hline type & 1 & 2 & 3 & 4 & 5 & 6 & 7 & 8 & 9 & 10 & 11 & 12 & 13 & 14 & 15 & 16 & 17 & 18 \\
\hline $\begin{array}{c}\mathbf{U}_{\mathbf{g}} \\
{\left[\mathbf{W} / \mathbf{m}^{2} \cdot \mathbf{K}\right]}\end{array}$ & \multicolumn{3}{|c|}{0,5} & \multicolumn{3}{|c|}{0,6} & \multicolumn{3}{|c|}{0,7} & \multicolumn{3}{|c|}{0,8} & \multicolumn{3}{|c|}{1,0} & \multicolumn{2}{|c|}{0,9} \\
\hline $\mathbf{g ~ [ - ]}$ & 0,6 & 0,5 & 0,4 & 0,4 & 0,5 & 0,6 & 0,6 & 0,5 & 0,4 & 0,6 & 0,5 & 0,4 & 0,4 & 0,5 & 0,6 & 0,6 & 0,5 & 0,4 \\
\hline
\end{tabular}

\section{Results of the parametric evaluation}

Temperatures immediately beneath the building are greatly influenced by the building itself. The manual of $\mathrm{E}+$ recommends the use of temperature in contact with the ground floor to be $2^{\circ} \mathrm{C}$ lower than the average internal temperature - this is true for large commercial buildings, where the heat loss around the perimeter of the building is less important. The manual also states that for best results "Slab" or "Basement" functions should be used to calculate the monthly average temperatures in contact with the ground. Using Slab is possible if the parameters of the external environment are entered: *epw file, soil parameters, the design 
detail of the ground structure (horizontal or vertical thermal insulation) and dimension of the building to calculate monthly values of temperature. Due to the relatively large uncertainty surrounding the boundary conditions, assessing the temperature of the floor construction in contact with the subsoil is based on a monthly average temperature as shown Tab. 3. Results from this parametric simulation are shown in Fig.3, which illustrates the possible range of annual energy demand of a House.
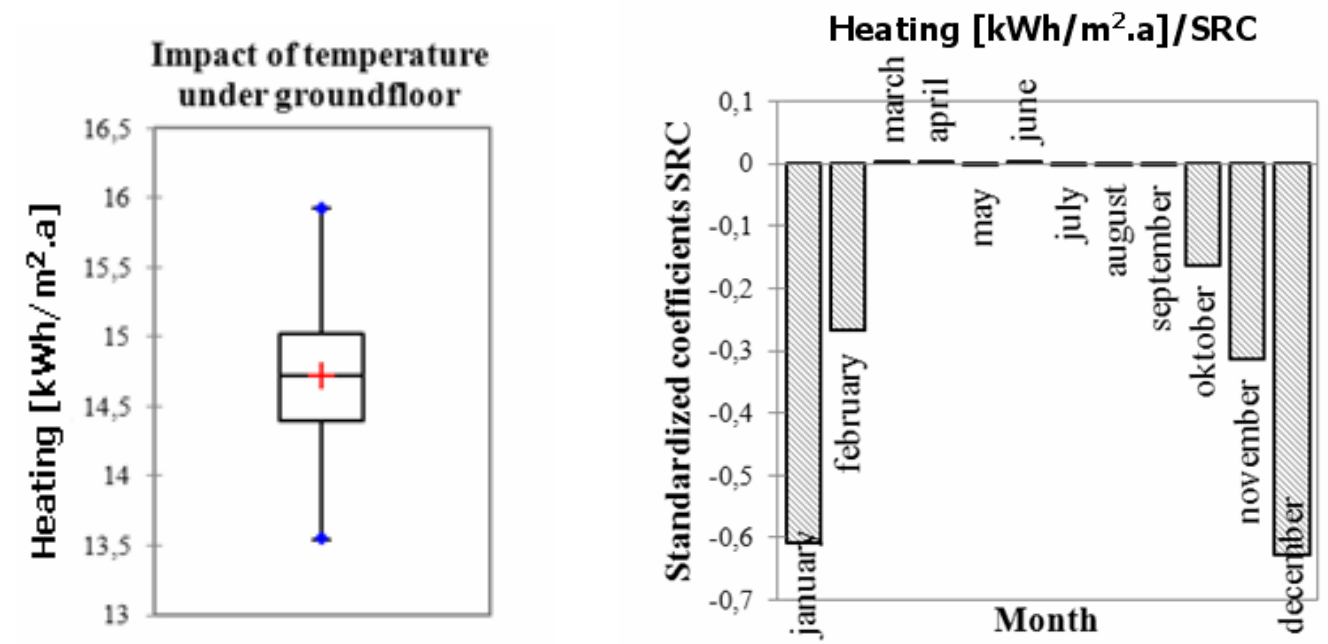

Figure 3: Range of heating demand - impact of temperature under the ground-floor

Outside boundary conditions (*epw files in simulation software) are the next uncertainty input into the simulation due to the long time requirements for observation [7] of the outdoor temperature and global intensity of solar rise. Fig. 4 shows the impact scenario that future weather has on the annual energy demand of a house and the thermal comfort of a house in summer (expressed by the Time of discomfort in summer [hr], where indoor operative temperature exceeds the limit). *Epw files of future weather were automatically generated from Meteonorm software [8].

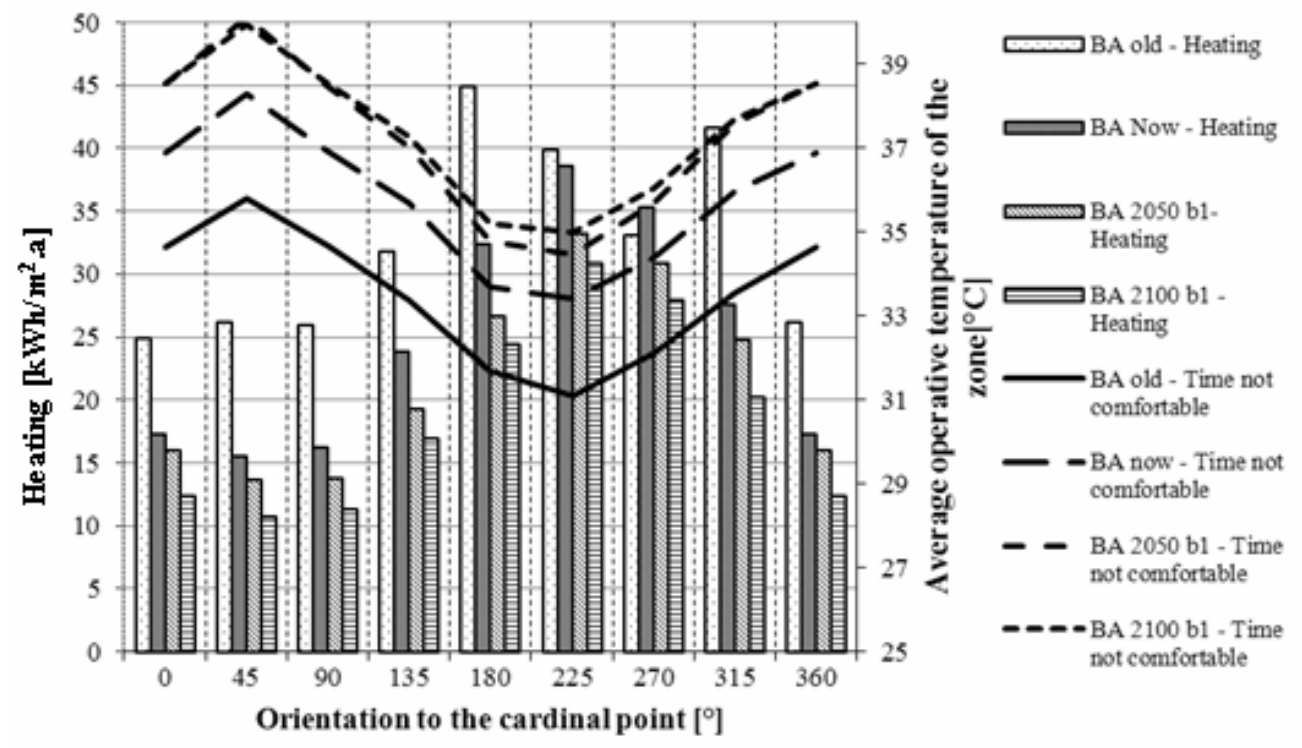

Figure 4: Impact of future weather on heating demand and thermal comfort 
In summer conditions indoor temperature is acutely important, as it is used in accordance with standard EN 15251 to evaluate adaptive temperature comfort. It means that no active cooling system is used and is therefore applicable for naturally ventilated buildings. The evaluated house makes use of external movable shading blinds. These blinds are controlled in the simulation as shown in Table 5. The impact of regulation and shading control on indoor operative temperature and adaptive thermal comfort is shown in Fig. 5, 6.
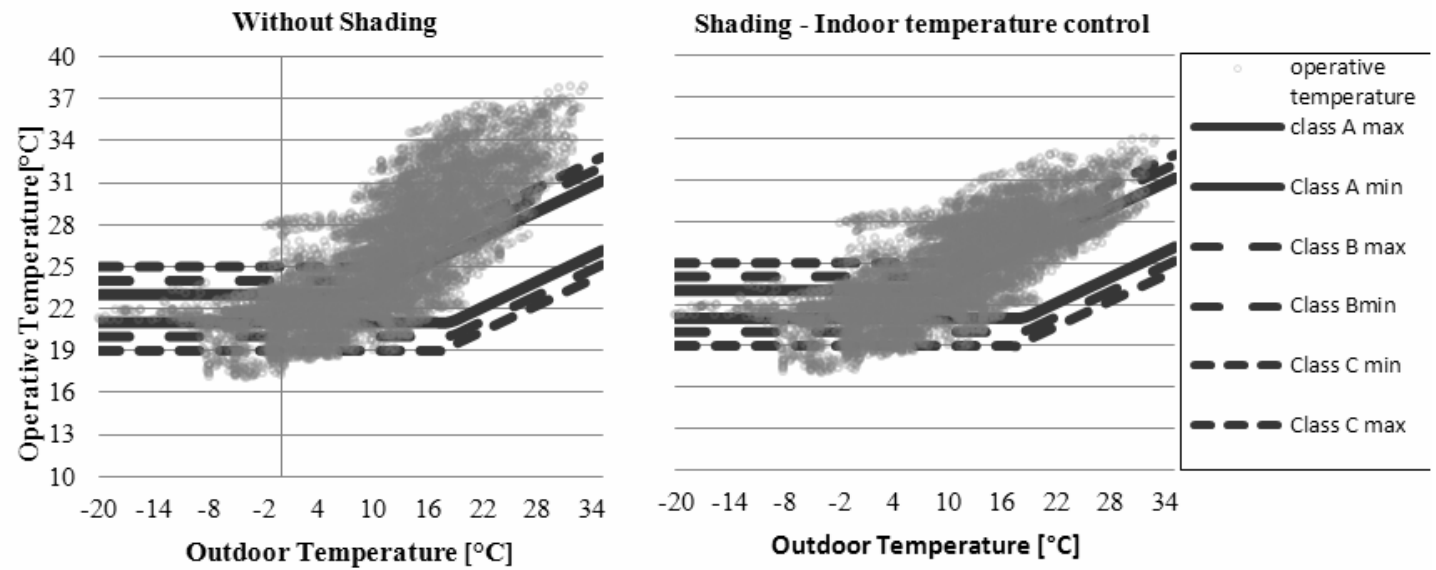

Figure 5: Left - without shading, right - shading with indoor temperature control
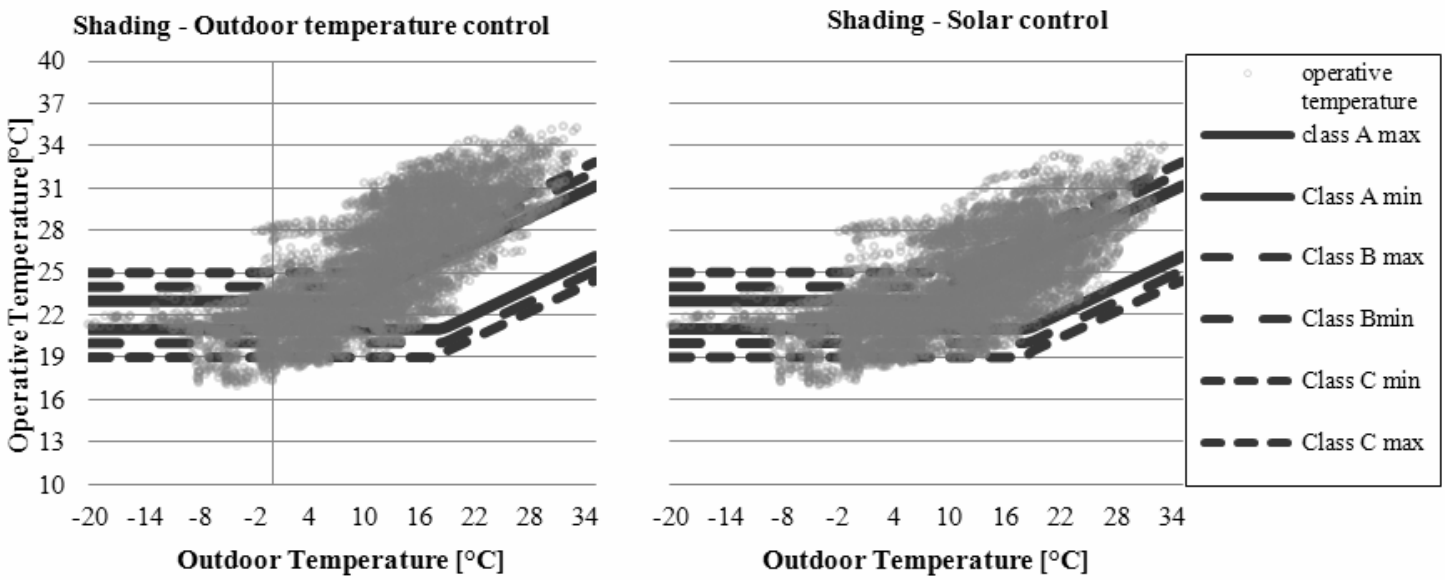

Figure 6: Left - outdoor temperature control, right - solar control

Frequencies of indoor operative temperature as the results of the shading scenario are shown in Fig. 7.

Glazing systems are is particularly more sensitive to parameter fluctuations when considering annual energy consumption and thermal comfort in summer. Therefore the next parametric simulation regards the influence of thermal (Ug) and optical (g) properties of glazing. Parameters of the considered glazing system are listed in Table 6 . The sensitivity of this 
parameter acting on the mentioned criteria is shown in Fig. 8, where sensitivity of overheating is expressed in \% terms when the operative temperature exceeds $26^{\circ} \mathrm{C}$.

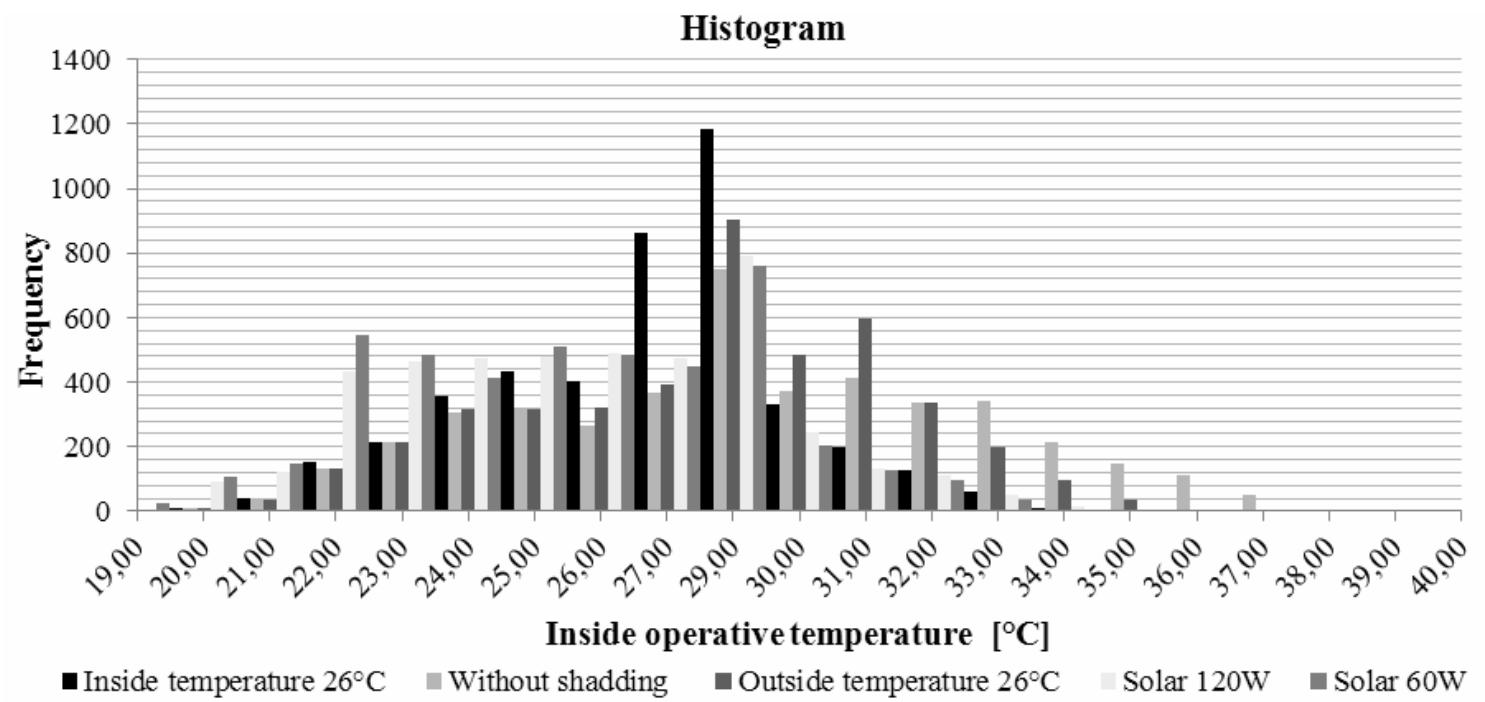

Figure 7: Frequency of indoor operative temperature for windows shading

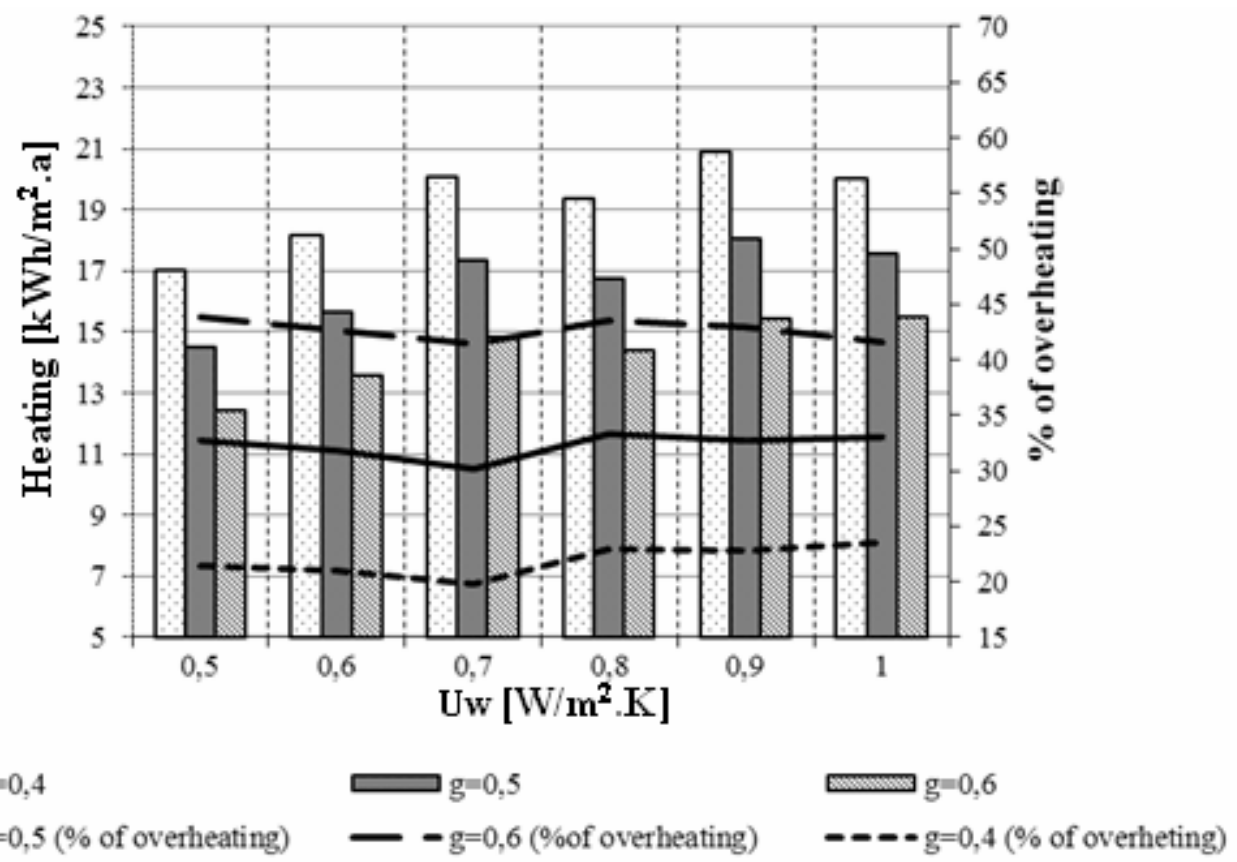

Figure 8: Sensitivity of glazing system on annual heating demand (left side) \% of overheating (right side).

Generally a glazing system is more sensitive to annual energy consumption and thermal comfort during summer. These two are almost adverse, if we improve one criterion the second criterion will deteriorate. Indoor conditions - thermal comfort in summer can be improve with natural and mechanical ventilation, or night ventilation. 


\section{Conclusion}

For the accurate simulation of buildings it is very important to define boundary conditions. From this aspect - the MonteCarlo is a good tool for determining sensitivity and uncertainty analysis based on stochastic selection random. Boundary conditions of ground-floor temperature in contact with the ground are uncertain and depend on many factors (insulation within the groundfloor slab - horizontal and vertical insulation, construction detail of the connection of external wall with ground-floor etc.) Fig.3 depicts a possible range of heating demand of a house dependent on these boundary conditions. In low energy buildings, where a higher ratio of heat losses and heat gains exist it is important to pay attention to the summer period and risk of overheating. It is therefore essential to consider the thermal and optical properties of windows and transparent structures Fig.8. Protection against overheating in summer by shading windows can be insured in a number of ways. Automatic outside movable shading blinds regulated by the intensity of solar irradiation seems to be most advantageous for thermal comfort in summer Fig.5 and Fig.6.

\section{Acknowledgements}

"This publication is the result of the Project: The use of a virtual laboratory for designing energyefficient buildings. Project 052TUKE-4/2013."

\section{References}

[1] SMITH S., T., Modeling thermal loads for a non-domestic building stock. Associating a priori probability with building form and construction - using building control laws and regulations. PhD Thesis, June 2009. Available online: $<$ http://etheses.nottingham.ac.uk/895/1/Thesis.pdf $>$.

[2] HOPFE CH., J., Uncertainty and sensitivity analysis in building performance simulation for decision support and design optimization. PhD Thesis, June 2009. Available online: $<$ http://alexandria.tue.nl/extra2/200911580.pdf> .

[3] KOTEK P., Metóda MonteCarlo jako nástroj optimalizace energetické náročnosti budov. PhD Thesis. 2008. Available online:

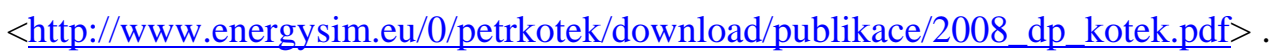

[4] Passive house Kittsee: $<$ http://www.pasivnydom.info/cat/1/uvod/> .

[5] EnergyPlus: Simulation software. Available online: $<$ http://apps1.eere.energy.gov/buildings/energyplus/ > .

[6] JE+ parametric simulation tool. Available online: $<$ http://www.iesd.dmu.ac.uk/ jeplus/wiki/doku.php>.

[7] Climate change 2007 : Synthesis Report. An assessment of the intergovernmental panel on climate change. $<\underline{\text { www.ipcc.ch }}>$

[8] Meteonorm: Climate software $<\underline{\text { http://meteonorm.com/ }>}$ 